\title{
VIERAS SISIMMÄSSÄ
}

Jean-Luc Nancy: Filosofin sydän. Suom. Susanna Lindberg (Corpus), Elia Lennes ja Kaisa Sivenius (Tunkeilija). Toim. Sami Santanen. Helsinki: Gaudeamus, 2010. $141 \mathrm{~s}$.

Kun Jean-Luc Nancyn teos Corpus (1992) ilmestyi käännettynä ranskasta suomeksi vuonna 1996, Helsingin Sanomat julkaisi kirjasta dosentti Juha Sihvolan laajan esittelyn. "Ruumis on kiihottava mutta koskematon pakkomielle", Sihvola otsikoi. Alaotsikko täsmensi kirjan merkitystä: "Jean-Luc Nancy tuo oman lisänsä vuosituhannen vaihteen filosofian muotikeskusteluun" (HS 21.9.1996). Sihvolan arvio Corpuksen käännöksestä oli ajankohtainen, sillä sen ilmestymispäiväksi oli suunniteltu Nancyn vierailuluentoa Helsingin yliopistoon. Vierailu kuitenkin peruuntui, sillä filosofin terveys esti matkan Suomeen. Nancyn tilaisuutta varten valmistelema esitelmä suomennettiin ja julkaistiin kirjana Heideggerin "alkuperäinen etiikka" (1998). ${ }^{1}$

Nyt julkaistava Filosofin sydän sisältää Corpuksen lisäksi kirjoituksen Tunkeilija (L'Intrus, 2000). Tunkeilija käsittelee juuri terveyttä ja sairautta - filosofin sydäntä itseään, Nancylle vuonna 1990 tehtyä elinsiirtoa. Uusi kokonaisuus ilmestyi viime vuoden huhtikuussa, jolloin Nancyn neljätoista vuotta odotettu vierailu lopulta toteutui.

\section{CORPUKSEN VAIHEITA}

Ruumista käsittelevä Corpus ilmestyy nyt hyvin erilaisessa ilmapiirissä kuin alun perin. Sekä Suomessa että ulkomailla on tapahtunut paljon filosofian alalla, ja Nancysta (1940) on tullut yksi ranskalaisen nykyfilosofian merkittävimmistä nimistä. $^{2}$

Nancy toimi Strasbourgin yliopiston filosofian professorina 1980-luvun lopusta vuoteen 2002 asti, jolloin hän jäi virastaan eläkkeelle. Hänen opetustoimintansa katkesi kuitenkin väliaikaisesti sydämensiirron vuoksi 1990-luvun alussa. Samalla vuosikymmenellä Nancy kirjoitti monet filosofisesti painavimmista teoksistaan, ja 2000-luvulla hän on edelleen julkaissut aktiivisesti sekä laajoja teoksia että lyhyempiä kirjoituksia.

Useimmiten Nancy lasketaan Jacques Derridan (19302004) seuraajiin ja "postmodernien" ajattelijoiden joukkoon samoin kuin hänen pitkäaikainen työtoverinsa Strasbourgin yliopistosta, Philippe LacoueLabarthe (1940-2007). 19701990-luvuilla Nancy kirjoitti yhdessä Lacoue-Labarthen kanssa useita teoksia. Nancyn ja Lacoue-Labarthen elämäntyön merkitys ulottuu kauas nykyfilosofian perinteeseen: he ovat tuoneet yhteen ranskalaisen dekonstruktion ja saksalaisen idealismin tradition ja näin osoittaneet dekonstruktion historialliset lähtökohdat.

Kun Susanna Lindbergin käännös Corpuksesta julkaistiin, sen edustama ajattelu oli Suomessa uutta. Dekonstruktiofilosofit, ensi sijassa Derrida, olivat tulleet tutuiksi jo 1980luvulta lähtien, mutta suomennokset olivat edelleen harvassa. Laajalle yleisölle ja useimmille filosofian tutkijoillekin Nancy oli yhä varsin tuntematon nimi. Kuitenkin 1990-luvun puolivälissä Nancyn edustama ruumiillisuutta koskeva keskustelu oli "kohoamassa yhdeksi vuosituhannen vaihteen filosofian suosituimmista aiheista", kuten Helsingin Sanomien arvio ennakoi, sillä tuolloin kiinnostus fenomenologiaan ja etenkin Maurice Merleau-Pontyyn kas- 
voi voimakkaasti. Samalla arvion kirjoittaja totesi, että Corpuksen kompromissiton tyyli ja "kryptisyyteen asti tihentyneet oppineet kiteytykset", jotka "vaihtuvat varoittamatta hätkähdyttäviin sanaryöppyihin, [...] tempaavat romanttiset sielut mukaansa - ja yhtä varmasti kertovat väsyneelle analyytikolle, mistä löytää seuraavan saunan sytykkeen".

Saksalaisesta ja ranskalaisesta fenomenologiasta - ensi sijassa Edmund Husserlin, Martin Heideggerin ja Merleau-Pontyn tuotannosta-ponnistavan ruumiin ajattelun ja analyyttisen filosofian välinen vastakkainasettelu on säilynyt, mutta fenomenologian perinne on onnistunut vähin erin juurtumaan suomalaiseen keskusteluun.

\section{KIELESTÄ JA SUOMENNOKSESTA}

Ennen Corpuksen käännöstä tuskin yhtäkään Nancyn tekstiä oli ilmestynyt suomeksi. Kääntäjä Susanna Lindberg teki mittavan työn ja loi monille Nancyn ydinkäsitteistä vastineet, jotka sittemmin ovat paljolti vakiintuneet suomenkieliseen keskusteluun. ${ }^{3}$

Tärkein ja nykypäivää ajatellen kauaskantoisin käännösratkaisuista lienee ranskan sanan sens suomentaminen "mieleksi". Sens on Nancyn tuotannossa tiheimmin esiintyviä käsitteitä, ja samalla se on hänen avaimensa ruumiin filosofiaan. Ensi sijassa Nancy haluaa erottaa sanan sens "merkitystä" ilmaisevasta sanasta signification. Samoin mieli on jotakin muuta kuin asioiden syy, perusta tai sisältö. Suomen sanalla "mieli" on riittävästi vivahteita, jotta se edes osin tavoittaa ranskan sens'in semanttiset ulottuvuudet: mielekkyyden, merkityksen, suunnan, aistin ja tunnun. Ehkä juuri tuntu vastaa kaikkein alkuperäisimmin sanan sens lukuisia käännösmahdollisuuksia (ks. Lindberg, "Saatesanat", s. 21). Kuten Nancy mainitsee myös esseessään "Extension de l'âme" (2002), ruumis ei tiedä, se voi vain tuntea. ${ }^{4}$ Lähes yhtä merkityksellistä on sanan exposition kääntäminen Corpuksessa "altistumiseksi" ja "alttiiksi asettumiseksi". Exposition viittaa ruumiin avoimuuteen, kykyyn ja haluun olla alttiina maailmalle ja maailmaa kohti (être-à) eli $e k$-sistoida sen sijaan, että ruumis ymmärrettäisiin itseensä sulkeutuvaksi substantiaaliseksi kokonaisuudeksi.

Ehkä enemmän kuin mikään toinen Nancyn teoksista juuri Corpus hyödyntää uudissanoja ja ranskan kielen vivahteita. Erityisesti Nancya kiehtovat samalla tavoin ääntyvät sanat ja monimerkityksisyys - esimerkiksi ranskan homonymiat "sang", "sens", "sans" ja "100" (s. 107). Siten erottamaton osa Corpuksen kieltä on sen materiaalisuus. Nancyn eräänlainen esikuva tässä suhteessa on Heidegger, joka tulkitsee sanoja, etsii niiden etymologista alkuperää ja osoittaa, että tutuksi luultuihin asioihin kätkeytyy usein ehtymätön vieraus. Corpuksessa kieli tulee esiin ruumiillisuudessaan, mikä yhdistää Nancyn aiemmin käsittelemät kysymykset materiaalisuuden ja konkreettisuuden filosofiaan.

\section{RUUMIS}

Corpuksen filosofinen merkitys on edelleen yhtä ajankohtainen kuin teoksen ilmestyessä 1990-luvun alussa tai silloin, kun se julkaistiin suomeksi ensi kertaa. Myöhemmin, vuonna 2000, Jacques Derrida julkaisi monisatasivuisen teoksen Le toucher, Jean-Luc Nancy, jossa hän nimittää Nancya "kaikkien aikojen suurimmaksi koske- tuksen ajattelijaksi". ${ }^{5}$ Derridan kirjan lähtökohtana on juuri Corpus, joka kirjoittajan mukaan on jopa nykypäivän vastine Aristoteleen tutkielmalle Sielusta (De anima).

Corpus on kirja ruumiin olemisesta, jossa yhdistyvät sen ilmiselvyys ja mahdottomuus - mahdotonta on ennen kaikkea tavoittaa ruumis filosofisen ajattelun avulla. Nancyn mukaan kukin ruumis on niin todellinen, materiaalinen ja ainutkertainen, että se pakenee kaikkia käsitteitä ja haltuunoton keinoja.

Corpus muodostuu lyhyistä luvuista, joissa Nancyn monet käsitykset ja avainsanat kertautuvat yksi toisensa jälkeen. Vastakohdista sitkein ja myös Corpuksen kannalta tärkein on Nancyn mukaan hengen ja ruumiin jaottelu, ajatus, että olisi olemassa platonilainen tai hegeliläinen "idea" ruumiista. Tämänkaltaiset yksinkertaistavat metafyysiset dikotomiat Nancy haluaa säännönmukaisesti ylittää - hengen ja materian ohella hän purkaa länsimaisen filosofian tärkeimpiä erotteluja: käsityksiä sisä- ja ulkopuolesta, osista ja kokonaisuuksista, tuntemisesta ja ajattelusta tai älystä.

Monet kirjan ilmaisuista ovat latinankielisiä. Suurin merkitys näistä on sanoilla hoc est enim corpus meum, joilla Nancy aloittaa Corpuksen (s. 27-29). Nämä ovat kristillisen ehtoollisen asettamisen sanat, jotka Nancyn mukaan ilmentävät kristinuskon ja erityisesti katolisuuden halua tehdä poissaolevasta, kadonneesta ruumiista läsnä oleva ja saattaa henki lihaksi. Kristinusko haluaa siis nähdä ruumiin ja aistia sen, jopa koskea sitä. Pyrkimyksenä on ottaa haltuun tämä korpus tässä, vakuuttua ruumiin aineettomasta ideasta, määrittää ja objektivoida 
se. Ruumis on varmuus, Nancy kirjoittaa, ja varmuus saavutetaan ottamalla ruumis omaksi, syömällä se - näin omaksi otettu ruumis on samalla vieras ja hirviömäinen.

Kirja siis alkaa inkarnaation "pakkomielteellä", jonka Nancy purkaa pohjia myöten. Ruumiin idean lihallistamisen sijasta hän omaksuu kaiken maailmaa koskevan tiedon alkuperäksi ruumiin, joka on ensi sijassa oma ruumiini, jokin, jota mikään ajattelun prosessi tai kielen ilmaus ei pysty objektivoimaan: Nancyn mukaan ruumis on ikuisesti puheen tuolla puolen. Tällainen ruumis jää vaille lopullisia määreitä, sillä se on aina vasta tulossa joksikin ja jonkinlaiseksi. Ruumis aisteineen ja ulottuvuuksineen jää käsitteiden ja ideoiden tavoittamattomiin, sillä se suuntautuu itsestään ulospäin kohti maailmaa ja toisia ruumiita. Siksi ruumis ei ole typistettävissä sanaksi eikä materiaksi, sillä se tunkeutuu aina niiden nimettömille rajapinnoille ja tapahtuu ainoastaan oman ulko- ja sisäpuolensa tai hengen ja aineen rajalla ja niiden rajana.

Ruumista ei ole myöskään olemassa vailla painoa, sitä tilaa ja painon voimaa, jonka todellinen rumis, toisin sanoen korpusten olemassaolo, kulloinkin syrjäyttää. Näin ruumis on partes extra partes (s. 46-47). Tämä tarkoittaa, että kaikki kappaleet ovat toistensa ulkopuolella ja niillä on oma tilansa, avoin alue tai väli, jota extra ilmaisee. Vain siksi, että on olemassa välitiloja, ruumis voi ottaa tilat ja paikat haltuunsa ja omikseen. Siten oleminen on paikkaa ja toimintaa eli praksista, kuten Nancy väittää esseessä Heideggerin "alkuperäinen etiikka". Näin hän esittää, että oleminen on korpusten olemista ja niiden keskinäisiä praktisia suhteita.
Siksi korpus ei ole subjekti eikä substanssi, eli se on ikuisesti vailla kiinteää olemusta, "päätä ja häntää". Ruumiit ovat olemassaolon paikkoja, sillä olemassaoloa ei ole ilman paikkaa; siten myös olemassaolo on luonteeltaan kiistämätöntä ja ilmeistä. Cogito, ajatteleva minä, tarjosi René Descartesille epäilyksettömän toden ja varman alkuperän; Nancylle vain ruumis voi kaikista maailman olioista olla tarpeeksi kirkas ja selvä, koska oma ruumis on maailmaa koskevien kokemusten kannalta epäilyksetön.

Nancyn tyyli todentaa kirjan tarkoituksen: ruumista ei voida selittää väitelausein, sillä ruumis on mahdollista vain näyttää, panna alttiiksi ja aukoa sen ulottuvuudet. Lukijan huomio kiinnittyykin Nancyn suosimien luetteloiden ja fragmenttien loputtomuuteen. Niiden tarkoitus on tehdä ruumis näkyväksi: ruumis voi olla esimerkiksi "[m]uodostumisen ja muovailun anatomiaa", ja siksi "pitäisi puhua ruumiintilojen, olemistapojen, ulkonäköjen, hengitysten, kävelytapojen, lamaannusten, tuskien, mielihyvien, karvoitusten, kiertymisten, kahinoiden, massojen anatomiasta" (s. 91).

Rakenteeltaan kirja on kaukana perinteisestä filosofisesti argumentoivasta teoksesta. Ennemminkin Corpus on tyyliltään esseemäinen, jopa kaunokirjallinen, ja sille ovat ominaisia nopeat rytminvaihdokset. Toteamukset, vastaväitteet ja paradoksit seuraavat toistaan, kun ruumista koskevat käsitykset ajautuvat lopulta ratkeamattomiin ristiriitoihin. Kieli on yhtä aikaa tiivistä, täsmällistä ja monikerroksista, vaikeaa ja tarkkaa; sen viitteet ja lainaukset muihin filosofeihin ja ruumiin teorioihin ovat lukemattomat. Teoksen kieli vahvistaa Nancyn dekonstruktionistisen ajatuksen: ruumis ei sulkeudu sanoiksi. Ruumiista ei voida puhua, ja silti - tai siksi - siitä on lakkaamatta puhuttava. Corpus ei tyhjene.

\section{TUNKEILIJA RUUMIISSA}

Filosofin sydämen päättävä Tunkeilija olisi helppoa lukea vain Corpuksen jälkikirjoitukseksi, mutta lyhyt essee on paljon enemmän. Se on filosofinen sairaskertomus, ja luullakseni Nancyn teksteistä omakohtaisin. Näin siitäkin huolimatta, ettei teksti ole psykologisessa mielessä henkilökohtainen, vaan pyrkii luomaan tavan ajatella omaa ruumista - ruumista, joka osoittautuu itselleni vieraaksi. Jos Corpus pyrki antamaan ilmauksen ruumiille joka on ennen kaikkea omani, Tunkeilija luopuu tämän ajatuksen ilmeisyydestä: sen keskipisteenä on oman ytimestä löytyvä väistämätön vieraus.

Tunkeilijan aiheena ovat Nancyn 1990-luvulla puhjenneet terveysongelmat, sydämen toiminnan heikkeneminen, vuosikymmenen alussa tehty sydämensiirto ja sen hoidosta myöhemmin seurannut imusolmukesyöpä. Elia Lenneksen ja Kaisa Siveniuksen kääntämän Tunkeilijan alkuvaiheet sijoittuvat siis Corpuksen kirjoittamisajankohtaan, kuten esseen alkusanat kirjoittanut Sami Santanen huomioi. Samoihin aikoihin Nancy julkaisi monet merkittävimmistä teoksistaan; esimerkiksi Une pensée finie ilmestyi vuonna 1990, Le sens du monde $1993 \mathrm{ja}$ Être singulier pluriel 1996.

Tunkeilijan kysymys koskettaa siis minän ja toisen suhdetta, identiteettiä ja vierautta. Nämä vastakohdat kyseenalaistuvat hetkellä, jolloin vieras asettuu filosofin sisimpään. Essee alkaa asetelmalla, joka muistuttaa Derridan poh- 
dintaa vieraanvaraisuudesta: mitä tarkoittaa vieraan toivottaminen tervetulleeksi ja mitä varaukseton vieraanvaraisuus vaatii vieraan vastaanottajalta, jos vieras tuo aina mukanaan erilaisuuden ja konfliktin mahdollisuuden?

Nancy kuvaa tekstissään, miten sydämen rappeutuminen ja sen lääketieteelliset tutkimukset tekevät elimestä omistajalleen paradoksaalisesti vieraan ja ulkoisen. Näin sydän muuttuu representaatioksi itselle ja joukoksi elintoimintoja (s. 130). Elinsiirto tuottaa käänteisen kokemuksen. Uusi sydän lyö, mutta sen vierautta vahvistaa kokemus siitä, että siirretty sydän, taloksi asettunut tunkeutuja, on kutsumaton ja kuitenkin samalla isäntänsä elinehto. Siirretyn sydämen omistaja on toinen henkilö, joka on menettänyt henkensä. Vain hänen sydämensä, lahjoituksensa, jatkaa toimintaa, se jatkaa toisen ihmisen elämää tämän sisimmässä. Kenen elämää?

Nancy avaa lukijalle näin ajatukset tutkimattomasta muukalaisuudesta minän ytimessä ja itseidenttisyyden särkymisestä. Vieraus ja ulkopuolisuus omaksi luullun ytimessä korostuvat Nancyn kuvauksissa hänen kokemistaan hoitotoimenpiteistä. Kokemus elimen vieraudesta kaksinkertaistuu, kun estolääkityksestä huoli-

1. Nancy, Jean-Luc (1998) Heideggerin "alkuperäinen etiikka", suom. Kaisa Sivenius, Helsinki: Loki.

2. Muita Nancyn ruumista käsitteleviä tekstejä ovat mm. "De l'âme" (1994; ilmestynyt mm. teoksessa Corpus, Paris: Métailié, 2000) ja teos 58 indices sur le corps (Québec: Nota bene, 2004), joka sisältää myös esseen "Extension de l'âme" (2002). matta seuraa hylkimisreaktio. Tämä aiheutuu siirretyn sydämen ja sen vastaanottajan immuunijärjestelmien keskinäisestä poikkeavuudesta.

Vasta parantamiseen tähtäävät hoidot paljastavat tunkeilijan luonteen. Ihminen käy itselleen vieraaksi, kun osoittautuu, että tunkeilevuus moninkertaistuu ja hylkimisreaktio synnyttää yhä uusia oireita. Nancy toteaa, että ihmisen identiteetin takaa viime vaiheessa immuniteetti: vain immuniteetin ansiosta olemassaolo voi olla itsenäistä. Kuten Corpuksessa kuvatussa ruumiiden maailmassa, nyt vieraus sisimmässä syvenee ja löytää uusia kosketuspintoja. Vieraus alkaa iskeä sisältäpäin, ja pakon edessä ruumis altistuu sille äärettömiin: hoidot seuraavat toistaan, synnyttävät uusia oireita, heikentävät vastustuskykyä. Kuoleman mahdollisuuksia on lopulta lukemattomia, kunnes saapuu "tunkeutujan perikuva", syöpä ja sen vaatimat raskaat parannuskeinot (s. 137). Tunkeilija rinnastuu näin esimerkiksi Susan Sontagin syöpäkertomukseen Sairaus vertauskuvana (1978), joka tarkastelee sairauden metaforisia ulottuvuuksia.

Nancy päättää Tunkeilijan kuvaukseen syöpähoidoista, jotka viimeistään jättävät minän paikalle tyhjän identiteetin. Sen tilalle asettuvat lopulta kivut,

\section{vi it te e t}

3. Corpuksen tuottamaa työtä kääntäjälle kuvaa se, että kirja ilmestyi kokonaisuudessaan englanniksi vasta vuonna 2008 , kun taas muut Nancyn merkittävimmistä teoksista ja suuri osa hänen uudemmastakin tuotannostaan on käännetty englannin kielelle lähes tuoreeltaan.

4. Nancy, "Extension de l'âme", s. 74.

5. Derrida, Jacques (2000) Le tulehdukset ja muut oireet. Eksistenssin ehto on siis asettuminen oman itsen ulkopuolelle ja siten vieraus itseen nähden: "me" olemme aina "me muut", nous autres, sillä aina, kun ryhdymme puhumaan "meistä", puhumme kuin ulkopuolisen asemasta käsin - olemme siis tunkeilijoita keskuudessamme. Tätä asetelmaa Nancy on selvittänyt esimerkiksi teoksessaan La communauté désouvrée (1986). ${ }^{7}$

Hoitojen aikana filosofin elämää alkaa hallita lääketieteellinen teknologia. Nancy kysyykin, missä elämä on sydämessä, aivoissa, missä? Hän vastaa tähän, ettei elämä ole yksittäisessä elimessä, vaan jossakin ihmisen ulkopuolella: "'Minä' on enää vain muodollinen indeksi", Nancy toteaa (s. 137). Minun ja minän suhde kadottaa aiemman välittömyytensä, ja niiden lomassa ammottavat tila ja aika.

Tunkeilija on hyvin kauniisti kirjoitettu teksti vailla tunteilun häivää. Se saa jopa kysymään, voiko näin kauniisti kirjoittaa sairastamisesta. Vieraus ja olemassaolon äärellisyys tiivistyvät kokemukseen elämän ja eloonjäämisen häilyvästä suhteesta. Tälle rajalle Tunkeilija asettuu, keskellä tuttua joka osoittautuu meille vieraimmaksi.

Martta Heikkilä

toucher, Jean-Luc Nancy, Paris: Galilée, s. 14.

6. Derrida, Jacques (1997) De l'hospitalité (avec Anne Dufourmantelle), Paris: CalmannLévy.

7. Nancy, Jean-Luc (1990/1986) La communauté désouvrée, $\mathrm{Pa}$ ris: Bourgois, s. 207-208; Nancy (1990) Une pensée finie, Paris: Galilée, s. 16. 